\title{
O padrão entoacional das sentenças interrogativas parciais do português brasileiro em fala manipulada
}

\author{
Carolina Carbonari Rosignoli \\ Universidade de São Paulo (USP), São Paulo, São Paulo, Brasil \\ carolinarosignoli@gmail.com
}

DOI: http://dx.doi.org/10.21165/el.v46i1.1633

\begin{abstract}
Resumo
Este artigo tem por objetivo investigar padrões entoacionais de enunciados interrogativos parciais do dialeto paulista do português brasileiro, visando a caracterização prosódica dos diferentes tipos frásicos de enunciados interrogativos parciais. Este trabalho tem como base a teoria da Fonologia Entoacional (PIERREHUMBERT, 1980; PIERREHUMBERT; BECKMAN, 1988; LADD, 1996, 2008; JUN, 2005) numa visão integrada com a Fonologia Prosódica (SELKIRK, 1984; NESPOR; VOGEL, 1986). Um corpus inédito, obtido por gravação em tarefa de leitura controlada, foi transcrito e analisado entoacionalmente. Em acréscimo às pesquisas de Frota et al. (2011) e Moraes (2008), os resultados da presente pesquisa revelam que variações dos contornos nuclear e total são distintivas na configuração prosódica de cada tipo frásico.
\end{abstract}

Palavras-chave: português brasileiro; fonologia; prosódia; sentenças interrogativas parciais.

The intonational pattern of partial interrogative sentences of Brazilian Portuguese in manipulated speech

\begin{abstract}
This paper aims to investigate intonational patterns of partial interrogative sentences of the Paulista dialect of Brazilian Portuguese, in order to observe prosodic distinctions and similarities among them that define different clause types. This work is based on Intonational Phonology theory (PIERREHUMBERT, 1980; PIERREHUMBERT; BECKMAN, 1988; LADD, 1996, 2008; JUN, 2005) in a view integrated with Prosodic Phonology (SELKIRK, 1980; NESPOR; VOGEL, 1986). A new corpus, which was formed by recording reading tasks in a linguistically organized manner was transcribed and analyzed based on the intonation. Working with an original corpus and in addition to Frota et al. (2015) and Moraes (2008), the results of the present research reveal that variations in the nuclear and total contours are distinctive in the prosodic configuration of each clause type.
\end{abstract}

Keywords: Brazilian Portuguese; phonology; prosody; partial interrogative sentences. 


\section{Introdução}

Este trabalho é vinculado ao projeto "Atlas Interativo da Prosódia do Português" (Interactive Atlas of the Prosody of Portuguese, doravante, InAPoP) ${ }^{1}$ e ao projeto de mestrado intitulado "A prosódia dos enunciados interrogativos do dialeto paulista do português brasileiro: análise da produção". ${ }^{2}$ Nosso objetivo principal é a investigação de padrões entoacionais associados às sentenças interrogativas parciais do português brasileiro (doravante, PB), as quais, conforme classificação sugerida por Frota et al. (2012-2014) e Mateus et al. (2003), correspondem às perguntas QU-, ou seja, às que apresentam uma palavra interrogativa ${ }^{3}$ como marca morfossintática da interrogação, conforme exemplo em (01):

(01) Quem é ela? ${ }^{4}$

Neste artigo, serão consideradas apenas as interrogativas com QU- deslocado, ou seja, fora de seu lugar canônico na estrutura sintática. Por exemplo, na sentença "Como você preparou o bolo?", a palavra QU- "como" aparece na periferia esquerda da estrutura sintática, fora de sua posição canônica, enquanto adjunto adverbial. No caso dessa sentença, se fosse produzida com a palavra QU- in situ, seria realizada da seguinte forma: "Você preparou o bolo como?". Conforme Mioto e Kato (2005), em PB, sentenças interrogativas com a palavra QU- deslocada apresentam uma frequência de $65,75 \%$ nas produções de sentenças interrogativas em PB, contra apenas $8,84 \%$ de frequência de realizações de sentenças interrogativas com a palavra QU- in situ. A investigação da prosódia de interrogativas parciais com elemento QU- in situ está fora do escopo deste trabalho e é um tema a ser abordado em estudos futuros.

O objetivo específico deste artigo é a caracterização prosódica das sentenças interrogativas parciais da variedade paulista do $\mathrm{PB}$, a partir da descrição suprassegmental da curva melódica encontrada nessas sentenças, com base no sistema descritivo sugerido pela Fonologia Entoacional numa visão integrada com a Fonologia Prosódica (conforme seção "Quadro teórico e trabalhos prévios" do presente artigo). Essa caracterização prosódica viabiliza a identificação de possíveis semelhanças e diferenças na curva entoacional em diferentes tipos frásicos interrogativos (ver seção "Classificação dos tipos frásicos" deste artigo), em função dos diversos contextos extralinguísticos que envolvem a produção de sentenças interrogativas e que, por sua vez, transmitem seu significado pragmático através da entoação.

${ }^{1}$ O projeto "Atlas Interativo da Prosódia do Português" (InAPoP), coordenado pela Profa. Dra. Sónia Frota e em desenvolvimento na Universidade de Lisboa, tem por objetivo a construção de um atlas interativo da prosódia do português, acessado livremente por uma plataforma online (http://www.fl.ul.pt/LaboratorioFonetica/InAPoP/), contemplando a variação prosódica, entoacional e rítmica do português, incluindo a cobertura completa do português europeu (doravante, PE) quanto a esses três aspectos, e contando ainda com variedades do PB ao longo da costa do Atlântico, assim como variedades do português falado na África.

2 Projeto de Mestrado desenvolvido no Programa de Pós-graduação em Filologia e Língua Portuguesa da Faculdade de Filosofia, Letras e Ciências Humanas da Universidade de São Paulo, com apoio da FAPESP (processo número 2015/07257-2).

${ }^{3}$ Como palavras interrogativas, Mateus et al. (2003) consideram pronomes e advérbios interrogativos como: qual(is), quanto(a)(s), quando, quem, onde, como, o que, quê, o quê, por que, por quê, para que.

${ }^{4}$ Palavra QU- sublinhada. 
Este artigo se encontra organizado nas seguintes subseções: (i) a seção "Quadro teórico e trabalhos prévios" apresentará o quadro teórico no qual se ancora este trabalho e os resultados prévios de outros autores sobre o mesmo tema; (ii) a seção "Materiais e métodos" trará informações sobre os corpora empregados na investigação que originou este artigo bem como sobre a metodologia da coleta, análise e interpretação de dados; (iii) a seção "Análise de dados e discussão" contará com os dados obtidos e sua interpretação dentro do enquadramento da fundamentação teórica; e (iv) por sua vez, a seção "Considerações finais" trará nossas conclusões e encaminhamentos futuros, com base nos resultados alcançados.

\section{Quadro teórico e trabalhos prévios}

Este trabalho tem como base uma visão integrada entre a teoria da Fonologia Entoacional (PIERREHUMBERT, 1980; PIERREHUMBERT; BECKMAN, 1988; LADD, 1996, 2008; JUN, 2005) e a Fonologia (SELKIRK, 1984, 1986, 2000; NESPOR; VOGEL, 1986, 2007).

A Fonologia Entoacional propõe a interpretação de significados pragmáticos de uma maneira linguisticamente organizada, a partir do conjunto de características suprassegmentais das sentenças. Desse modo, é proposta uma descrição universal para a entoação, tomando como pressuposto básico uma organização fonológica da entoação. A entoação é tratada pela Fonologia Entoacional a partir de contornos entoacionais, que são uma sequência de unidades, os eventos tonais, alocadas em pontos específicos da cadeia segmental (PIERREHUMBERT, 1980; PIERREHUMBERT; BECKMAN, 1988, entre outros). Para Cruz e Frota (2011), os eventos tonais de uma língua comportam-se como morfemas que codificam informações semânticas e pragmáticas, seja isoladamente ou em sequência. A representação fonética da sequência de eventos tonais consiste no contorno da frequência fundamental (F0). Para essa teoria, os eventos tonais definem-se uns em relação aos outros a partir do critério da altura. Desse modo, aos tons altos atribui-se o símbolo $\mathrm{H}$ (high) e aos tons baixos, L (low). Os tons podem ser monotonais ( $\mathrm{H}$ ou L) ou ainda bitonais, complexos (ascendentes ou descendentes). Atribuem-se ainda outras anotações para eventos tonais específicos, como, por exemplo, a marcação de tom mais alto, numa mesma sentença, em relação a um outro tom alto imediatamente anterior (com a representação de upstep " $i$ " antecedendo " $\mathrm{H}$ " - "degrau acima") e a marcação de tom mais baixo em relação a um tom alto imediatamente anterior, mas ainda assim alto, dentro da sentença (com a representação de downstep "!" antecedendo "H"- "degrau abaixo"). Os eventos tonais compreendem dois tipos: Os acentos tonais são associados a sílabas proeminentes na cadeia segmental e são representados pelo alvo de altura (H, L, LH ou HL) seguido de asterisco (*). Os tons relacionados a fronteiras são os tons de fronteira (boundary tones: L\%, H\%, HL\% ou $\mathrm{LH} \%$ ), relacionados a fronteiras de constituintes prosódicos maiores (por exemplo, fronteira de fim de enunciado), e os acentos frasais (phrasal accents: $\mathrm{L}^{-}$ou $\mathrm{H}^{-}-$ conforme a notação de Pierrehumbert), ${ }^{5}$ relacionados a fronteiras de constituintes prosódicos menores (por exemplo, fronteira de fim de sintagma).

\footnotetext{
${ }^{5} \mathrm{Na}$ literatura linguística brasileira sobre entoação do PB, "acento frasal" é o termo mais utilizado para a tradução de phrasal accent.
} 
Por sua vez, a Fonologia Prosódica (SELKIRK, 1984, 1986, 2000; NESPOR; VOGEL, 1986, 2007) prevê uma integração entre o contorno entoacional, conforme a Fonologia Entoacional propõe, e a interface entre estruturas fonológicas e sintáticas. $\mathrm{O}$ fluxo da fala é organizado de maneira hierarquizada dentro de domínios prosódicos que interagem com outros componentes gramaticais para além da fonologia. A evidência para essa hierarquia é proveniente da operação de regras fonológicas que operam no interior e na juntura de alguns domínios.

Verifica-se, porém, que nem sempre as estruturas sintáticas e fonológicas coincidem. Certas regras fonológicas, por exemplo, podem ter, como domínio de aplicação, constituintes não correspondentes aos derivados pela morfossintaxe, o que evidencia a não isomorfia obrigatória entre constituintes morfossintáticos e constituintes fonológicos.

Conforme Nespor e Vogel (1986, 2007), uma sentença pode ser vista como uma organização hierárquica de constituintes prosódicos diferentes, indo do menor constituinte ao maior, sendo eles: (i) sílaba, (ii) pé, (iii) palavra fonológica, (iv) grupo clítico, (v) frase fonológica, (vi) frase entoacional e (vii) enunciado fonológico. A Figura 1 apresenta uma possível representação dessa estrutura hierárquica, conforme Nespor e Vogel (1986):

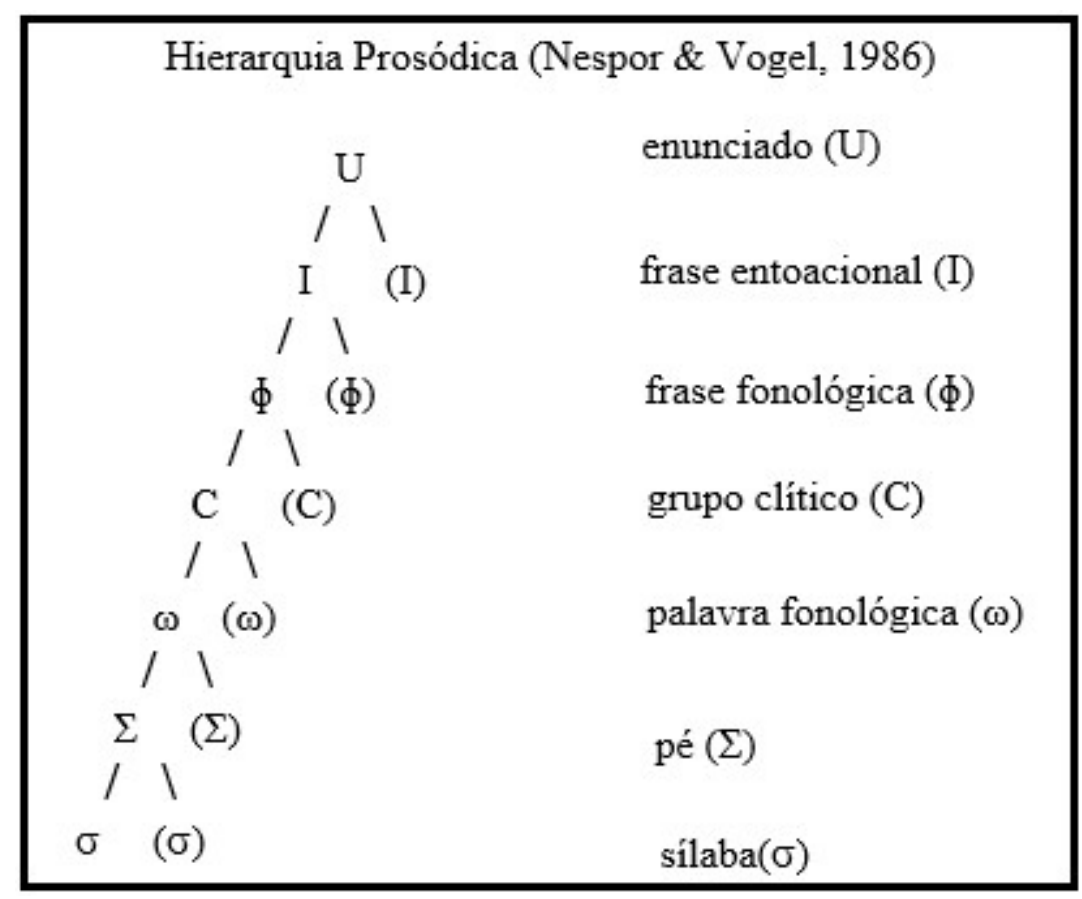

Figura 1. Representação da estrutura hierárquica dos constituintes prosódicos conforme Nespor e Vogel (1986)

Em nossa investigação, são considerados os seguintes constituintes prosódicos: a palavra fonológica $(\omega)$, a frase fonológica $(\phi)$, a frase entoacional (I) e o enunciado fonológico (U). Isso porque são esses os domínios prosódicos mais relevantes na associação de eventos tonais ao contorno entoacional das sentenças declarativas do PB, conforme já descrito na literatura: o $\phi$ (FROTA; VIGÁRIO, 2000; TENANI, 2002) e a $\omega$ (FERNANDES, 2007a, b; TENANI; FERNANDES-SVARTMAN, 2008; TONELI, 2014) são os domínios relevantes para a associação de acentos tonais ao contorno 
entoacional, o $\phi$ (FERNANDES, 2007a, b; TENANI; FERNANDES SVARTMAN, 2008) é o domínio relevante para a associação de acentos frasais e, por sua vez, o I (FROTA; VIGÁRIO, 2000; TENANI, 2002; FERNANDES, 2007a, b; SERRA, 2009) e o U (TENANI, 2002; SERRA, 2009) são os domínios relevantes para a associação de tons de fronteiras.

Quanto aos trabalhos prévios sobre o padrão melódico de interrogativas parciais em PB desenvolvidos à luz da Fonologia Entoacional, destacamos Moraes (2008) e Frota et al. (2015).

As pesquisas de Moraes (2008) e Frota et al. (2015) apontam que o contorno entoacional padrão para interrogativas parciais, de modo geral, pode ser definido como $\mathrm{H}+\mathrm{L} * \mathrm{~L} \%$. Esse contorno, descendente, difere daquele associado para as interrogativas globais ${ }^{6}$, que possuem, segundo os mesmos autores, contorno nuclear majoritariamente ascendente. Frota et al. (2015) indicam um contorno nuclear ascendente (L+H) possível associado a esse tipo de sentença interrogativa, mas infrequente. Moraes (2008) aponta também para um pico em F0 alinhado à palavra QU- como característica prosódica das interrogativas parciais.

Neste artigo, trataremos da descrição entoacional do contorno total dos enunciados interrogativos globais, e não apenas do contorno nuclear. Nossa hipótese é que o padrão entoacional global dos enunciados interrogativos parciais do $\mathrm{PB}$, e não só o contorno nuclear, é relevante na caracterização de seus diferentes tipos frásicos.

\section{Materiais e métodos}

Nesta seção, serão dadas informações detalhadas sobre o corpus e sobre os procedimentos metodológicos empregados no desenvolvimento deste trabalho.

Os dados selecionados para esta investigação são de um corpus inédito, composto por 49 enunciados interrogativos parciais, de seis tipos frásicos, conforme a classificação apresentada no Quadro 1, a seguir. Para cada tipo frásico, foram formuladas sentenças interrogativas com cada uma das palavras QU- definidas por Mateus et al. (2003) (ver nota de rodapé 3).

\section{Classificação dos tipos frásicos}

A classificação de sentenças interrogativas parciais, adaptada para o desenvolvimento deste trabalho, levou em conta os tipos frásicos apresentados pelo projeto InAPoP e pelo trabalho de Mateus et al. (2003). Definiu-se a nomenclatura especificada no Quadro 1 para fins de análise e classificação das sentenças interrogativas globais. Cabe acrescentar que, conforme apresentado no Quadro 1, entende-se por interrogativas parciais neutras aquelas que não apresentam uma resposta esperada ao que se pergunta. As interrogativas parciais não neutras, por sua vez, apresentam uma expectativa de resposta.

\footnotetext{
${ }^{6}$ Interrogativas globais são perguntas que esperam por resposta "sim" ou "não" e possuem, em PB, estrutura sintática de superfície idêntica às declarativas (FROTA, 2014), por exemplo: “O João vai à festa?".
} 
Quadro 1. Classificação dos tipos frásicos de interrogativas parciais

\begin{tabular}{|c|l|l|l|}
\hline $\begin{array}{c}\text { Tipos } \\
\text { Frásicos }\end{array}$ & Sigla & \multicolumn{1}{|c|}{ Especificação } & \multicolumn{1}{c|}{ Exemplo } \\
\hline \multirow{4}{*}{ Neutras } & $P B I$ & $\begin{array}{l}\text { Parcial Neutra de Busca de } \\
\text { Informações }\end{array}$ & O que fizeram no feriado? \\
\cline { 2 - 4 } & $P N C$ & Parcial Neutra Coordenativa & $\begin{array}{l}\text { Para que você precisa de uma camisa e } \\
\text { qual você prefere? }\end{array}$ \\
\hline \multirow{5}{*}{ Não-Neutras } & $P A C$ & Parcial Não-Neutra Confirmatória & $\begin{array}{l}\text { (Estão indo embora porque choveu). Por } \\
\text { que estão indo embora? }\end{array}$ \\
\cline { 2 - 5 } & $P A P$ & $\begin{array}{l}\text { Parcial Não-Neutra Confirmatória de } \\
\text { Pergunta }\end{array}$ & $\begin{array}{l}\text { (Por que você está triste?) Por que eu } \\
\text { estou triste? }\end{array}$ \\
\cline { 2 - 5 } & $P E D^{7}$ & Parcial Eco Disjuntiva & $\begin{array}{l}\text { Que horas eu acordo ou que horas eu } \\
\text { levanto? }\end{array}$ \\
\cline { 2 - 5 } & $P A A$ & Parcial Não-Neutra Antiexpectativa & Quem foram os responsáveis? \\
\hline
\end{tabular}

\section{Coleta de dados}

Os dados relativos à fala controlada foram coletados por meio de gravação realizada com gravador TASCAM H2-P2 (Frontier) e microfone de lapela Sennheiser, contando com três informantes mulheres, entre 20 e 40 anos, com ensino superior completo, paulistas e residentes em São Paulo, que repetiram cada sentença do corpus três vezes. Duas, das três repetições, foram transcritas e analisadas, totalizando 372 sentenças interrogativas parciais (49 sentenças x três informantes x duas repetições).

As três informantes produziram as sentenças a partir de uma tarefa de leitura controlada. As sentenças foram aleatorizadas computacionalmente e misturadas a sentenças distratoras. Cada repetição produzida pelas informantes apresentava uma ordem aleatória de apresentação, tanto das sentenças do corpus quanto das sentenças distratoras. As sentenças vinham acompanhadas de um contexto de produção, que não deveria ser lido, mas que era informação importante para a compreensão do significado pragmático das sentenças apresentadas e, portanto, para a produção da sentença. Em (02), vemos um exemplo de contexto oferecido às informantes, seguido pela sentença a ser produzida:

(02) Contexto: Perguntaram a você onde você está morando, mas você não sabe se entendeu bem o que foi indagado. Então você repete a pergunta, para ter certeza: Sentença produzida: Onde eu estou morando?

As sentenças foram transcritas e analisadas entoacionalmente por meio do software livre Praat (BOERSMA; WEENINK, 2014) e com base nos pressupostos teóricos da Fonologia Entoacional (ver seção "Quadro teórico e trabalhos prévios" deste artigo) e, especificamente para o português do Brasil (FROTA; VIGÁRIO, 2000; TENANI, 2002; FERNANDES, 2007a, 2007b; SERRA, 2009; TRUCKENBRODT; SANDALO; ABAURRE, 2009; VIGÁRIO; FERNANDES-SVARTMAN, 2010).

\footnotetext{
${ }^{7}$ A sigla PED diz respeito às interrogativas parciais $(\mathrm{P})$ não neutras eco $(\mathrm{E})$ disjuntivas $(\mathrm{D})$.

8 Conforme apontam Cruz e Frota (2011), as interrogativas parciais eco ocorrem em contexto de confirmação de uma pergunta mal ouvida ou mal entendida. O interlocutor repete, então, a pergunta, de maneira a confirmar se ouviu bem.
} 


\section{Resultados: análise de dados e discussão}

Os enunciados interrogativos foram submetidos à análise prosódica, que consistiu na transcrição e na descrição de todos os eventos tonais associados ao contorno entoacional de cada enunciado.

Os resultados principais obtidos a partir da descrição e análise prosódica dos dados dizem respeito, sobretudo: (i) ao contorno nuclear observado para as interrogativas parciais e (ii) às características prosódicas específicas do contorno total que distinguem os tipos frásicos de interrogativas parciais.

\section{O contorno nuclear das interrogativas parciais}

De maneira geral, observamos um contorno nuclear majoritariamente ascendente associado às interrogativas parciais, diferentemente do que foi apontado anteriormente pela literatura (FROTA et al., 2015; MORAES, 2008). O Gráfico 1, a seguir, apresenta a frequência de ocorrência de contornos nucleares ascendentes, descendentes $\mathrm{e}$ monotonais baixos entre interrogativas globais.

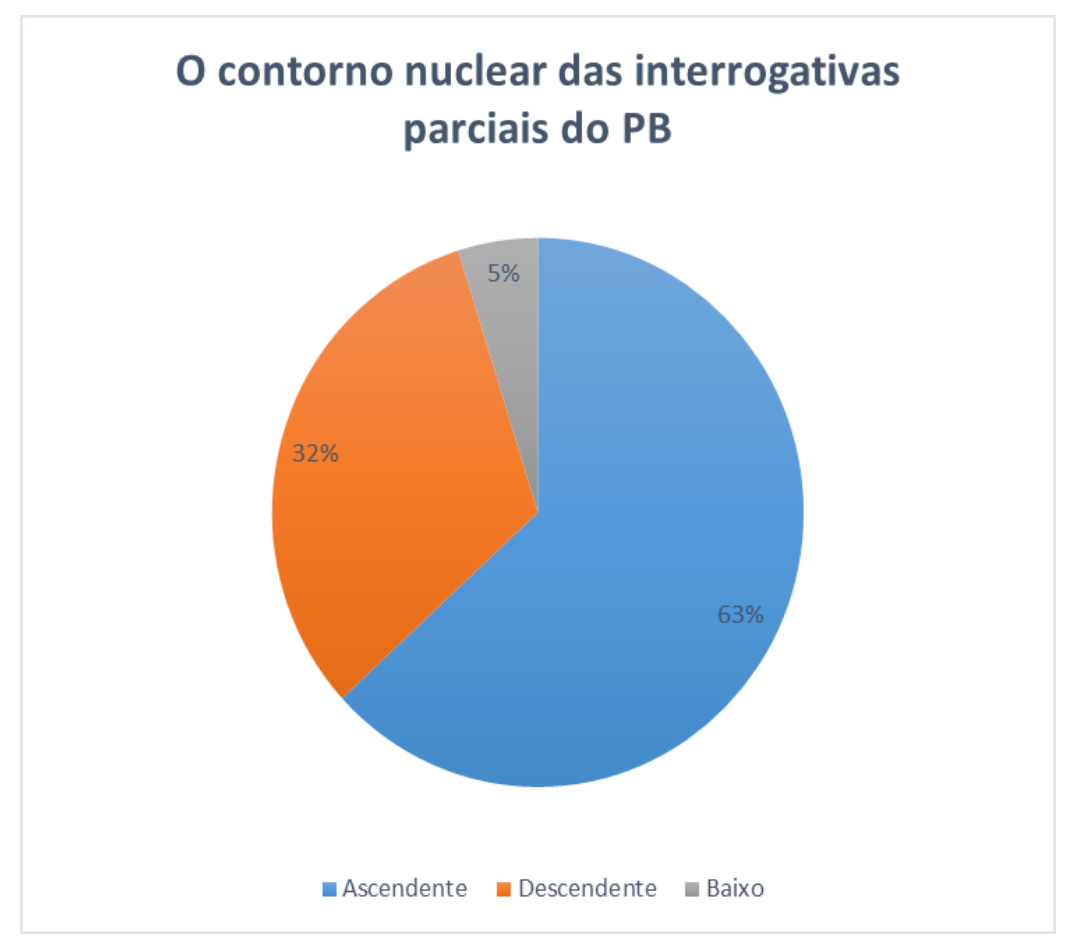

Gráfico 1. Frequência de ocorrência do contorno nuclear das interrogativas parciais do PB

Pela leitura do gráfico, é possível observar que a frequência de ocorrência de contornos ascendentes, 63\% (235 ocorrências), é bastante superior à frequência de ocorrência de contornos descendentes, 32\% (119 ocorrências), e de contornos baixos, 5\% (18 ocorrências).

Se levarmos em conta, porém, apenas as interrogativas parciais de busca de informação, consideradas neutras, ou seja, sem uma expectativa prévia de resposta (ver seção "Materiais e métodos" deste artigo), a frequência de ocorrência dos contornos entoacionais dos mesmos três tipos (ascendente, descendente e baixo) diverge do quadro geral de interrogativas parciais, conforme pode ser observado no Gráfico 2, abaixo. 


\section{O contorno entoacional das interrogativas parciais neutras de busca de informação}

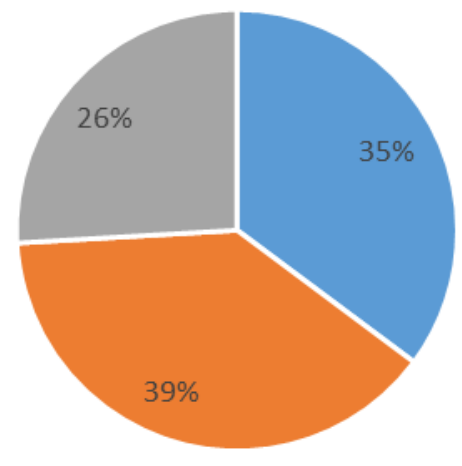

- Ascendente Descendente Baixo

Gráfico 2. Frequência de ocorrência do contorno nuclear das interrogativas parciais neutras de busca de informação do PB

O que pode ser observado é que o contorno nuclear mais comum é descendente, corroborando o que foi proposto tanto por Moraes (2008) quanto por Frota et al. (2015). As frequências de ocorrência de contornos ascendentes e descendentes é próxima para esse tipo frásico. ${ }^{9}$

A Figura 2, abaixo, apresenta a análise entoacional da sentença interrogativa parcial neutra de busca de informação, "O que fizeram no feriado?". É possível observar, nessa figura, o contorno entoacional ascendente, o mais comum às interrogativas parciais.

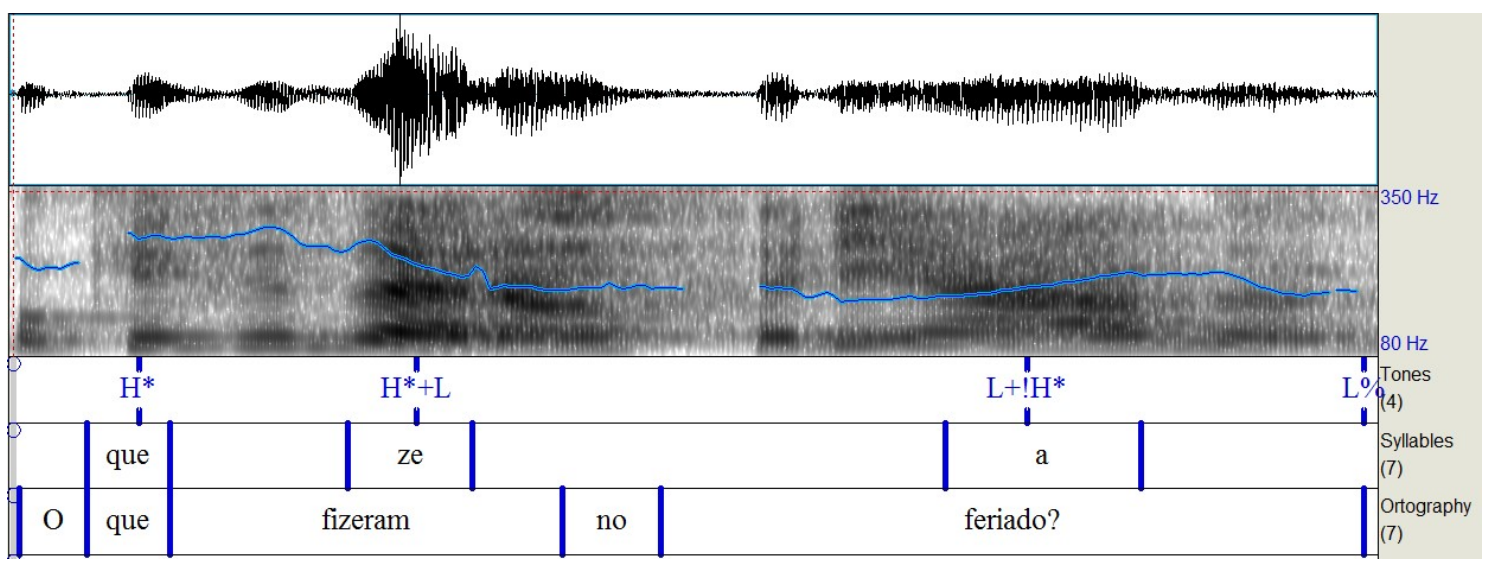

Figura 2. Análise entoacional da sentença interrogativa parcial neutra de busca de informação, "O que fizeram no feriado?", produzida por FC

\footnotetext{
${ }^{9}$ Cabe acrescentar que o tratamento estatístico de todos os dados incluídos no presente artigo está em andamento.
} 
O contorno nuclear da sentença cuja análise pode ser vista na Figura 2 é descrito como $\mathrm{L}+! \mathrm{H}^{*} \mathrm{~L} \%$. $\mathrm{O}$ acento tonal, $\mathrm{L}+\mathrm{H}^{*}$, ascendente, é seguido por tom de fronteira baixo, $\mathrm{L} \%$.

$\mathrm{Na}$ Figura 3, por sua vez, vemos um exemplo da mesma sentença, "O que fizeram no feriado?", produzida com um contorno entoacional descendente.

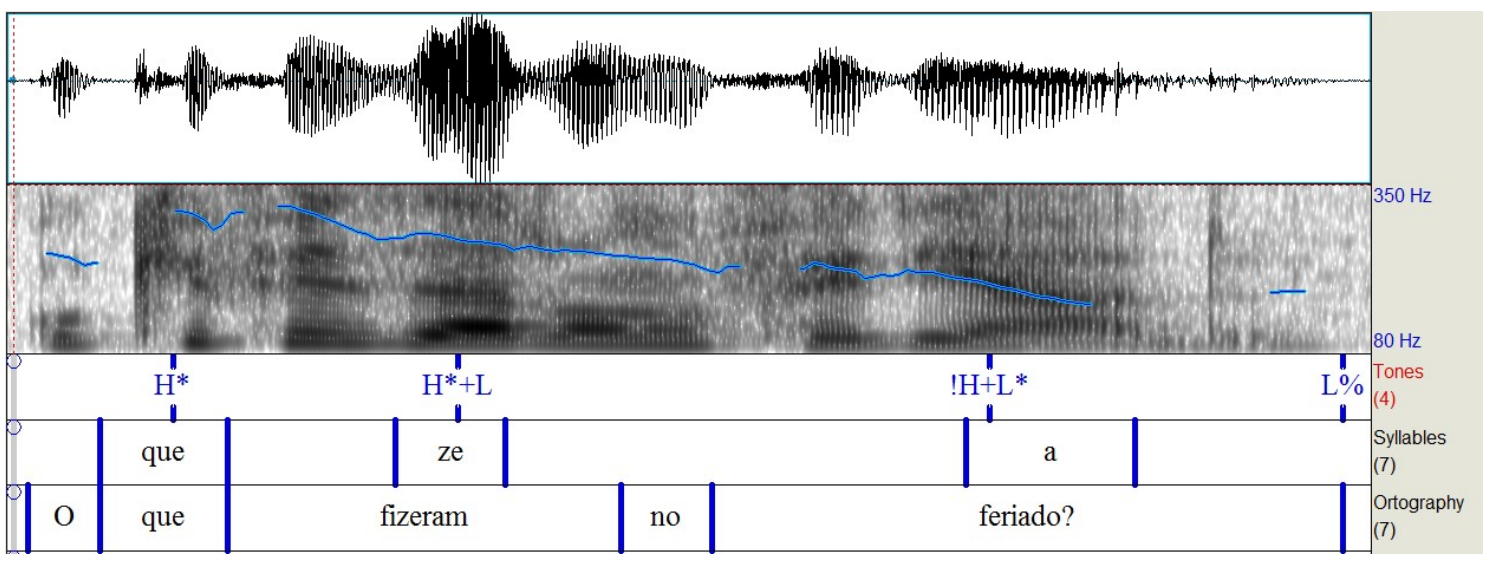

Figura 3. Análise entoacional da sentença interrogativa parcial neutra de busca de informação, "O que fizeram no feriado?", produzida por EF

É possível observar que, assim como no caso da sentença apresentada na Figura 2 , o tom de fronteira é baixo, L\%. Ambas as sentenças apresentam contorno entoacional semelhante na porção entoacional que precede o contorno nuclear das sentenças.

$\mathrm{Na}$ Figura 4, abaixo, observamos a ocorrência do contorno nuclear monotonal baixo, em outra produção da mesma sentença, "O que fizeram no feriado?".

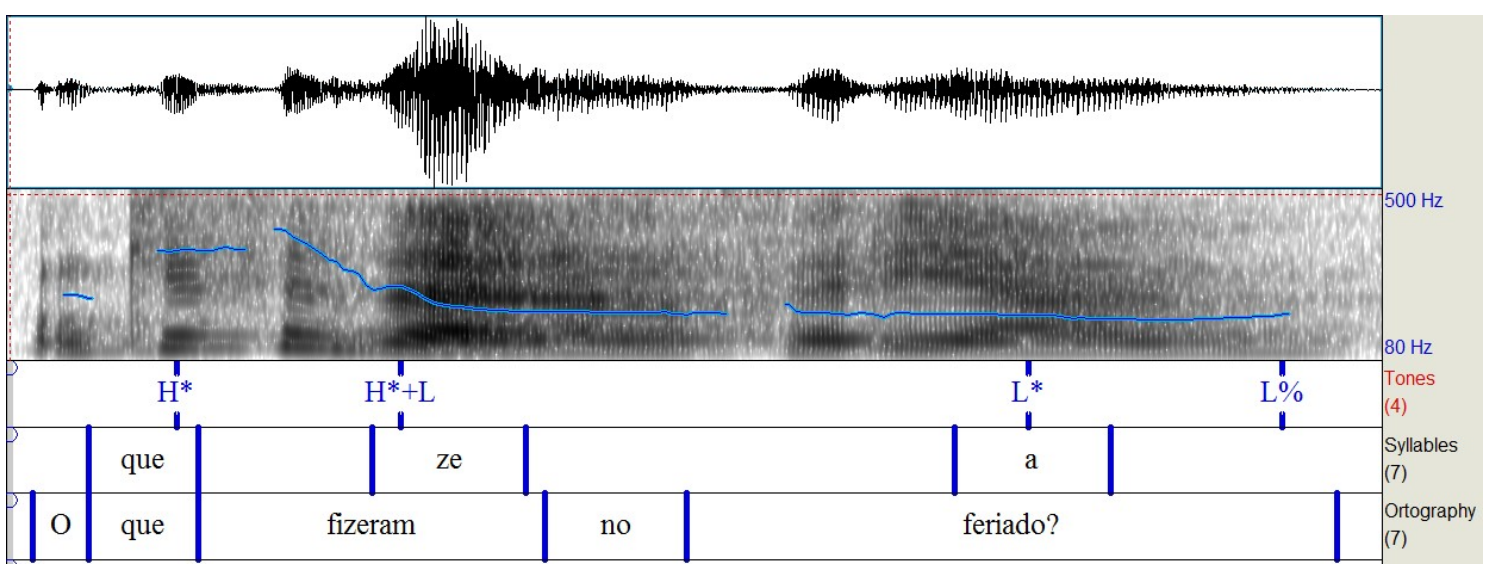

Figura 4. Análise entoacional da sentença interrogativa parcial neutra de busca de informação, "O que fizeram no feriado?", produzida por FC

$\mathrm{Na}$ Figura 4, observamos características entoacionais, associadas à porção anterior ao contorno nuclear, semelhantes em relação aos exemplos ilustrados pelas Figuras 2 e 3. Porém, no caso da sentença ilustrada pela Figura 4, o contorno nuclear é monotonal e baixo.

As Figuras 2, 3 e 4 apresentaram os contornos nucleares observados nas interrogativas parciais do $\mathrm{PB}$, respectivamente: contorno ascendente, descendente $\mathrm{e}$ monotonal baixo. 


\section{$O$ contorno total das interrogativas parciais}

Em relação à caracterização prosódica do contorno total das interrogativas parciais do $\mathrm{PB}$, os elementos mais relevantes dizem respeito: (i) à associação de tom $\mathrm{H}$ ou L+H à palavra QU-, ou seja, à primeira palavra prosódica do enunciado; (ii) à associação de acento frasal à fronteira de sintagma fonológico relacionada à marcação de foco e (iii) à densidade tonal das interrogativas parciais do PB.

Foi possível observar a associação de evento tonal $\mathrm{H}$ ou $\mathrm{L}+\mathrm{H}$ a $100 \%$ das sentenças interrogativas parciais analisadas. As Figuras 2, 3 e 4 configuram exemplos dessa associação de evento tonal à primeira palavra fonológica da sentença entoacional, que marca o pretonema, conforme Moraes (2008) e Silva (2011). De modo geral, o pico em F0 está associado à palavra QU- das interrogativas parciais, e não a seu contorno nuclear, independentemente de este ser ascendente ou descendente. Em ambos os casos, é possível a ocorrência de downstep associado ao contorno nuclear (como pode ser observado nas Figuras 2 e 3).

Quanto à associação de acento frasal à fronteira de sintagma fonológico em interrogativas parciais, observamos que esta associação marca focalização de elementos com ênfase. Observamos, porém, que essa associação é exclusiva das sentenças interrogativas parciais não neutras. As sentenças interrogativas parciais neutras não apresentam ênfase especial em nenhum item lexical e, portanto, não apresentam marcação prosódica de foco. As sentenças não neutras em geral, tanto declarativas quanto interrogativas, por sua vez, podem apresentar elemento focalizado, o qual, por vezes, é marcado a partir da associação de acento frasal, conforme afirmaram Fernandes (2007) e Frota et al. (2015), sobre as sentenças declarativas do PB, e Rosignoli e Fernandes-Svartman (2016), sobre as sentenças interrogativas. A Figura 5, abaixo, apresenta um exemplo dessa associação de acento frasal a elemento focalizado.

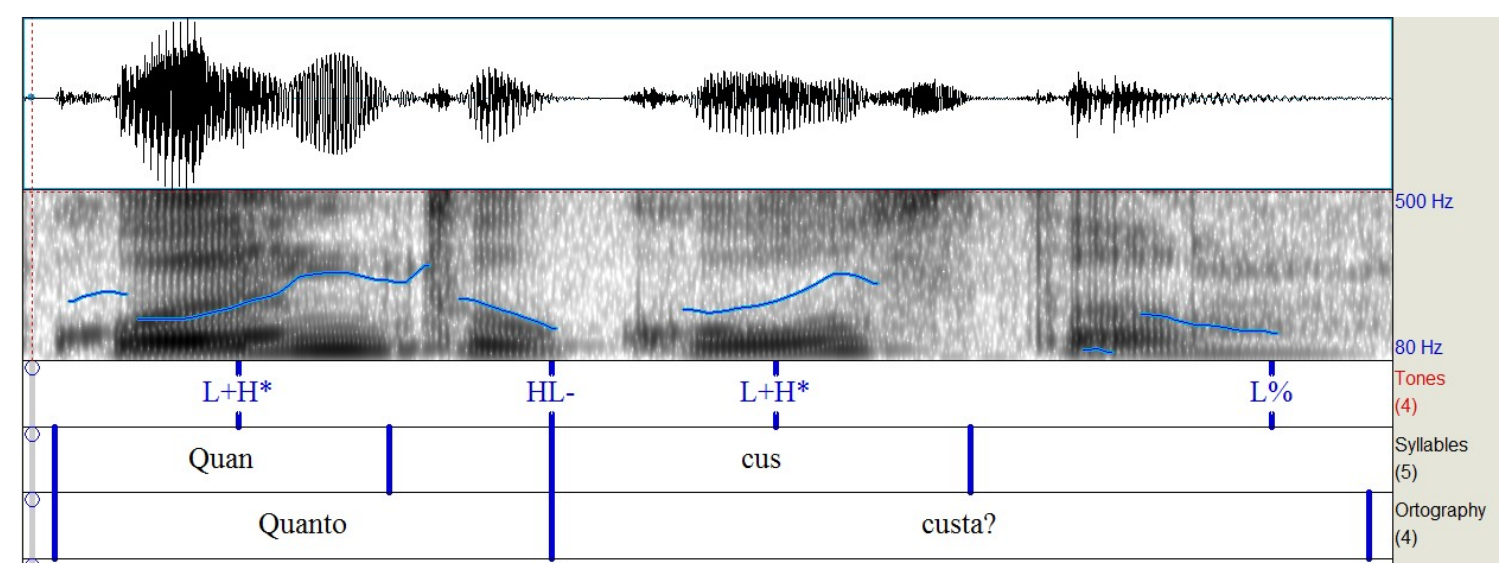

Figura 5. Análise entoacional da sentença interrogativa parcial não neutra de confirmação de pergunta, “Quanto custa?", produzida por MR

No caso do exemplo ilustrado pela Figura 5, o elemento focalizado é a palavra QU-, que recebe ênfase especial por se tratar de uma busca por confirmação. Já na Figura 6, vemos um exemplo de sentença que apresenta ênfase em outro elemento lexical que não a palavra QU-. Assim como no caso da sentença anterior, o foco recai sobre o elemento focalizado que recebe ênfase por se tratar de uma busca por confirmação. 


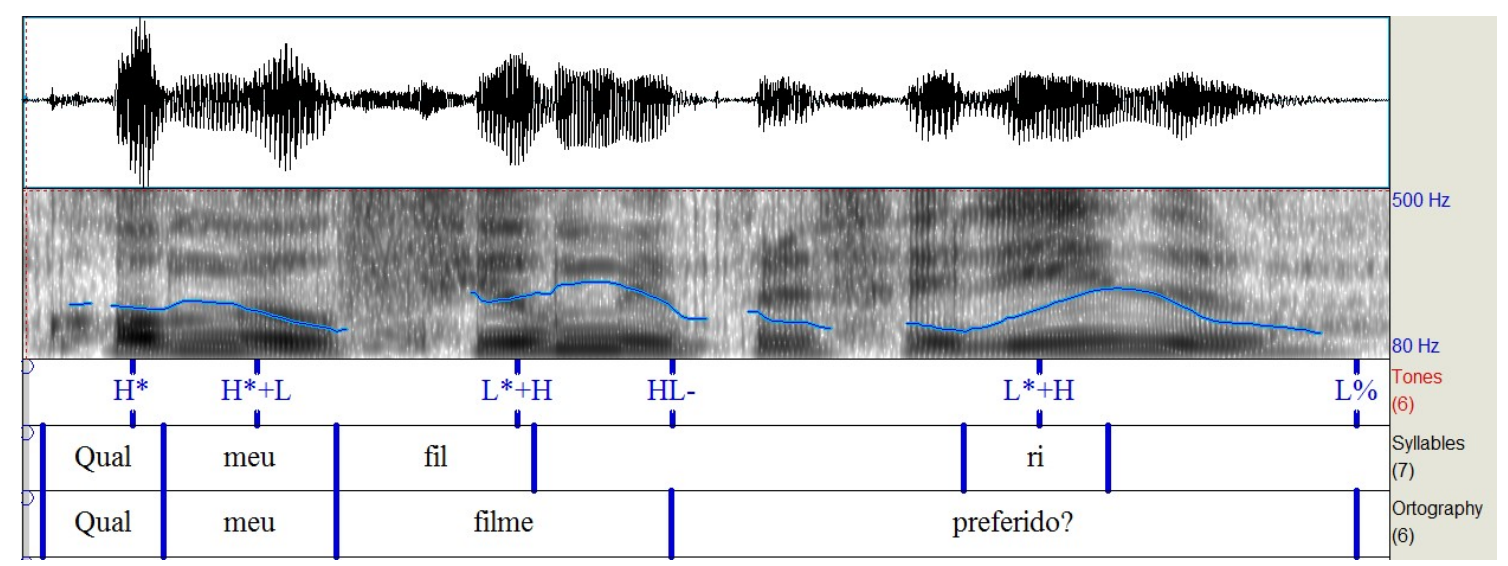

Figura 6. Análise entoacional da sentença interrogativa parcial não neutra de confirmação de pergunta, “Qual meu filme preferido?”, produzida por MR

Quanto à densidade tonal, que é a proporção entre eventos tonais alocados na cadeia segmental e a quantidade de palavras prosódicas encontradas no enunciado entoacional, e levando em conta que, conforme Frota e Vigário (2000), Tenani (2002) e Fernandes (2007a, b) (apud FERNANDES-SVARTMAN, 2012), em PB a densidade tonal é mais alta se comparada à densidade tonal observada no português europeu (doravante, PE), havendo a possibilidade de associação de evento tonal a todas as palavras prosódicas do enunciado e a obrigatoriedade de associação de evento tonal às palavras prosódicas cabeça de sintagma fonológico, observamos, para as sentenças interrogativas parciais do $\mathrm{PB}$, uma densidade tonal alta, de maneira geral.

$\mathrm{Na}$ Tabela 1, abaixo, é possível observar a densidade tonal das interrogativas parciais do PB. Na segunda linha da tabela, verificamos a densidade tonal observada em todas as sentenças interrogativas parciais, que é de $77 \%$. Na terceira linha da tabela, é possível observar a densidade tonal das sentenças interrogativas parciais neutras, de $80 \%$, enquanto que na quarta linha obtemos informações sobre a densidade tonal das sentenças parciais não neutras, de $76 \%$.

Tabela 1. Densidade tonal das interrogativas parciais do PB

\begin{tabular}{c|c|c|c}
\hline Tipo Frásico & Palavras prosódicas $(\omega)$ & Acentos Tonais & Densidade \\
\hline Parciais & 1265 & 973 & $77 \%$ \\
\hline Neutras & 372 & 297 & $80 \%$ \\
\hline Não neutras & 893 & 676 & $76 \%$ \\
\hline
\end{tabular}

Fernandes-Svartman (2012) apontou para uma densidade tonal de 90\% associada às sentenças declarativas neutras do PB. No caso das interrogativas parciais, de modo geral, observamos uma densidade tonal mais baixa mesmo para as interrogativas parciais neutras, que apresentam uma densidade tonal de dez pontos percentuais mais baixa quando comparada à densidade tonal das declarativas neutras. 


\section{Considerações finais}

Neste artigo, foram apresentados elementos que constituem a caracterização prosódica das sentenças interrogativas parciais do PB. Esses elementos dizem respeito não somente ao contorno nuclear, mas ao contorno total dessas interrogativas. Os resultados principais levantados compreendem: (i) a descrição dos contornos nucleares mais comuns como sendo ascendentes, mas com possibilidade de serem descendentes e monotonais baixos; (ii) a associação de evento tonal $\mathrm{H}$ ou $\mathrm{L}+\mathrm{H}$ a $100 \%$ das palavras QU- das sentenças parciais; (iii) a associação de acentos frasais a elementos focalizados exclusivamente em sentenças interrogativas parciais não neutras e (iv) à densidade tonal média de $77 \%$ em sentenças interrogativas parciais do PB.

Esses resultados corroboram a hipótese de que não apenas o contorno nuclear é responsável por transmitir significados pragmáticos de sentenças interrogativas parciais. O contorno total e suas características específicas, como as apontadas acima em (ii) e (iii), por exemplo, são características entoacionais que auxiliam na transmissão dos significados pragmáticos específicos dos diferentes tipos frásicos.

A presente pesquisa tem como próximos passos: (i) a análise estatística dos dados, de maneira a validá-los estatisticamente e reforçar os resultados já encontrados; (ii) a comparação dos dados de fala controlada com dados de fala semi-controlada; (iii) a investigação do ponto de vista da percepção se os contornos entoacionais descritos pelo ponto de vista da produção são perceptíveis e se suas características entoacionais são relevantes na percepção para a distinção de tipos frásicos.

\section{REFERÊNCIAS}

BOERSMA, P.; WEENINK, D. Praat: Doing Phonetics by Computer [Computer program]. Version 5.3. 82. 2014. Disponível em: <http://www.fon.hum.uva.nl/praat/>. Acesso em: 27 jun. 2015.

CRUZ, M.; FROTA, S. Prosódia dos tipos frásicos em variedades do Português Europeu: produção e percepção. Textos Seleccionados, XXVI Encontro da Associação Portuguesa de Linguística, Lisboa, APL, p. 208-225, 2011.

FERNANDES, F. R. Tonal association in neutral and subject-narrow-focus sentences of Brazilian Portuguese: a comparison with European Portuguese. Journal of Portuguese Linguistics, v. 6, n. 1, p. 91-115, 2007a.

Ordem, focalização e preenchimento em português: sintaxe e prosódia. 2007b. 415 f. Tese (Doutorado em Linguística) - Instituto de Estudos da Linguagem, Universidade Estadual de Campinas, Campinas, 2007b.

FERNANDES-SVARTMAN, F. R. A entoação das sentenças clibadas em português brasileiro e a interface sintaxe-fonologia. Filologia e linguística portuguesa, n. 14(1), p. 37-56, 2012.

FROTA, S. (Coord.). InAPoP - Interactive Atlas of the Prosody of Portuguese. Projeto de investigação científica (processo FCT PTDC/CLE-LIN/119787/2010). Universidade de Lisboa, 2012-2014. 
FROTA, S.; CRUZ, M.; SVARTMAN, F.; VIGÁRIO, M.; COLLISCHONN, G.; FONSECA, A.; SERRA, C.; SCHWINDT, L. C. Portuguese: Labelling intonational variation across varieties of European and Brazilian Portuguese. Workshop on Romance ToBI, Universitat Rovira i Virgili, 2011.

FROTA, S.; CRUZ, M.; FERNANDES-SVARTMAN, F.; COLLISCHONN, G.; FONSECA, A.; SERRA, C.; OLIVEIRA, P.; VIGÁRIO, M. Intonational variation in Portuguese: European and Brazilian varieties. In: FROTA, S.; PRIETO, P. (Eds.). Intonational variation in Romance. Oxford: Oxford University Press, 2015, p. 235-283. Disponível em: $<$ http://labfon.letras.ulisboa.pt/InAPoP/resources.html>. Acesso em: 15 jun. 2015.

FROTA, S.; VIGÁRIO, M. Aspectos de prosódia comparada: ritmo e entoação no PE e no PB. In: CASTRO, R. V.; BARBOSA, P. (Org.). Actas do XV Encontro Nacional da Associação Portuguesa de Linguística. v. 1. Coimbra: Associação Portuguesa de Linguística, p. 533-555, 2000. Disponível em: $<$ http://labfon.letras.ulisboa.pt/InAPoP/resources.html>. Acesso em: 15 jun. 2015.

JUN, S-A. Prosodic Typology - The Phonology of Intonation and Phrasing. New York: Oxford University Press, 2005.

LADD, D. R. Intonational Phonology. Cambridge: Cambridge University Press, 1996.

2008. Intonational Phonology. $2^{\text {nd }}$ edition. Cambridge: Cambridge University Press,

MATEUS, M. H. M.; BRITO, A. M.; DUARTE, I.; FARIA, I. H.; FROTA, S.; MATOS, G.; OLIVEIRA, F.; VIGÁRIO, M.; VILLALVA, A. Gramática da Língua Portuguesa. 5. ed. Lisboa: Ed. Caminho, 2003. p. 460-479.

MIOTO, C.; KATO, M. As interrogativas Q do português europeu e do português brasileiro atuais. Revista da ABRALIN, v. 4, n. 1 e 2, p. 171-196, dez. 2005.

MORAES, J. The Pitch Accents in Brazilian Portuguese: analysis by synthesis. Laboratório de Fonética Acústica, Faculdade de Letras UFRJ/Faculdade de Letras UFRJ/CNPq, 2008.

NESPOR, M.; VOGEL, I. Prosodic Phonology. Dordrecht: Foris Publications, 1986. Prosodic Phonology: with a new foreword. Berlin: Mouton de Gruyter, 2007.

PIERREHUMBERT, J. The phonology and phonetics of English intonation. 1980. 402 f. Tese (Doutorado em Filosofia) - Massachusetts Institute of Technology, Cambridge, Mass, 1980.

PIERREHUMBERT, J.; BECKMAN, M. Japanese Tone Structure. Cambridge, Mass.: The Massachusetts Institute of Technology Press, 1988.

ROSIGNOLI, C. C.; FERNANDES-SVARTMAN, F. R. O padrão entoacional das sentenças interrogativas do português brasileiro em fala manipulada. Estudos Linguísticos, São Paulo, v. 45, n. 1, p. 60-72. 2016.

SELKIRK, E. O. Phonology and syntax: The relation between sound and structure. Cambridge: The Massachusetts Institute of Technology Press, 1984. 
. On derived domains in sentence phonology. Phonology Yearbook, n. 3, p. 371405, 1986.

. The interaction of constraints on prosodic phrasing. In: HORNE, M. (Ed.). Prosody: Theory and Experiment. Netherlands: Kluwer Academic Publishers, 2000. p. 231-261.

SERRA, C. R. Realização e percepção de fronteiras prosódicas no português do Brasil: fala espontânea e leitura. 2009. 241 f. Tese (Doutorado em Letras Vernáculas) Faculdade de Letras, Universidade Federal do Rio de Janeiro, Rio de Janeiro, 2009.

TENANI, L. E. Domínios prosódicos no português do Brasil: implicações para a prosódia e para a aplicação de processos fonológicos. 2002. $331 \mathrm{f}$. Tese (Doutorado em Linguística) - Instituto de Estudos da Linguagem, Universidade Estadual de Campinas, Campinas, 2002.

TRUCKENBRODT, H.; SANDALO, M. F. S.; ABAURRE M. B. M. Elements of Brazilian Portuguese intonation. Journal of Portuguese Linguistics, v. 8, p. 75-114, 2009.

VIGÁRIO, M.; FERNANDES-SVARTMAN, F. R. A atribuição de acentos tonais em compostos no português do Brasil. In: BRITO, A. M.; SILVA, F.; VELOSO, J.; FIÉIS, A. (Org.). XXV Encontro da Associação Portuguesa de Lingüística - Textos Seleccionados. Porto: Tip. Nunes, Ltda - Maia, 2010. v. 1, p. 769-786.

Recebido em: 30/08/2016

Aprovado em: 24/10/2016 